\title{
High Rigid [Mg(II)(N-PAA)] Complex Binds Excellently with BSA Macromolecule and SARS-CoV-2 Virus Main Protease
}

\author{
M. Santhiya ${ }^{1} \&$ T. Lurthu Pushparaj ${ }^{2 *}$ \\ ${ }^{\text {I} D e p a r t m e n t ~ o f ~ C h e m i s t r y, ~ U G, ~ T . ~ D . ~ M . ~ N . ~ S ~ C o l l e g e, ~ T a m i l ~ N a d u-627113, ~ I n d i a . ~}$ \\ $2^{2 *}$ Assistant Professor, Department of Chemistry, PG, T. D. M. N. S College, Tamil Nadu-627113, India. Email: chemlurthu2006@gmail.com
}

DOI: http://doi.org/10.46382/MJBAS.2021.5205

Copyright: @2021 M. Santhiya et al. This is an open access article distributed under the terms of the Creative Commons Attribution License, which permits unrestricted use, distribution, and reproduction in any medium, provided the original author and source are credited.

In an increasing number of countries, worldwide serious public health threats have arisen due to ongoing pandemic of coronavirus 2019 (COVID19), caused by the serious acute respiratory syndrome of coronavirus 2 (SARS-CoV-2). Although no clinically approved antiviral medicines and vaccines are available for COVID-19, clinical trials for COVID-19 patients have been attempted. A new strategy in modern pharmaceutical discovery research is targeted drug design. We describe a new $\mathrm{Mg}$ (II) complex containing N-Phenyl Anthranilic Acid, as a synthesis and structural characterization herein. Gaussian energy calculations were used to calculate the insilico-based basic energy calculation for potential and steric energy. The absorption behavior in neat solvent in the presence of 4.5 percent BSA, as well as the biological interaction of COVID-19 virus via molecular docking, has been summarized, with a direct or indirect focus on coordination chemistry. The complex absorbance spectra confirms the intra-ligand $\mathrm{n}-\pi^{*}, \pi-\pi *$, LCT, and MLCT charge transfer transitions. Furthermore, the complex in 4.5 percent BSA exhibit blue shift in absorption bands, which correspond to LCT and MLCT transitions as a result of polar and van der Waals interactions with BSA protein. The docking of COVID-19 virus (PDB: 6LU7) with various amino acid sequences in the ' $\mathrm{S}$ ' spike protein reveals a strong polar interaction of $-7.2 \mathrm{kcal} / \mathrm{mol}$. The complex's antiCOVID-19 nature is being investigated.

Keywords: N-Phenyl Anthranilic acid, Mg(II)complex, BSA Binding, Anti SARS-COV-2, Molecular Docking, M-Protease.

\section{Introduction}

Amine and hydroxide bases are also known for their bioactivities, which include antibacterial activity, anticarcinogenic, antimicrobial, and anti-malarial properties, as well as cytotoxic, anti-inflammatory, antibiotic, and antiparasitic properties. Heteroaromatic branches have become extremely relevant in chemistry in recent decades. Because of its presence of both hard nitrogen and oxygen donor atoms in the backbones of these ligands, transition metal ions of heterocyclic bases are really interesting. Some of these complexes have phenomenal physicochemical characteristics and genuinely valuable bioactive components [1,2].

Heteroatoms base ligands can synchronise as well as stabilise metal oxides throughout different oxidation states [3-6]. The heterocyclic base complexes have been used in catalytic reactions and as physiological proposed framework [7,8]. Over the last 20 years, there has been a growing interest in metal complexes of heterocyclic bases $[9,10]$ containing nitrogen and other donors. This is due to their stability, biological activity, and numerous applications [11] in a variety of fields such as oxidation catalysis, electrochemistry, and biological research. N-PAA (N-Phenyl Anthranilic Acid), also known as fenamic acid, is a mono-dentate ligand.

It serves as a scaffold for the synthesis of several non-steroidal anti-inflammatory drugs. It functions as an oscillator of membrane transport. It is widely seen as a precursor in medication, pharmaceutics, analytical chemistry, and biochemistry for the synthesis of biologically active compounds, comparative medical research, and metal ion determination [12]. Although some lanthanide complexes of N-phenylanthranilic acid are known, no 3d transition metal complexes have been published [13-15]. Magnesium occurs naturally in three stable isotopes: 
${ }^{24} \mathrm{Mg},{ }^{25} \mathrm{Mg}$, and ${ }^{26} \mathrm{Mg}$. Magnesium is the eleventh most abundant element in the human body by mass and is required by all cells and approximately 300 enzymes [16]. Magnesium ions are required for the function of hundreds of enzymes, and it interacts effectively with polyphosphate compounds such as ATP, DNA, and RNA. Recent research has shown that magnesium sulphate can be nebulized to alleviate the symptoms of acute asthma [17]. For the treatment of severe asthma attacks, it is commonly administered intravenously. Although magnesium sulphate is used to suppress ovulation in women with preeclampsia and eclampsia, and for foetus neuroprotective effects in premature labor, it has shown to be an inefficient tocolytic agent [18-22]. Bovine serum albumin (also known as BSA or "Fraction V") is a protein separated from bovine serum albumin. BSA is manufactured by Rockland in a variety of forms for use in pharmacology, cell biology, and bioengineering. In many applications, BSA is regarded as a universal blocking reagent because it has no effect on the functions of other proteins (enzymes) that do not require it for stabilization. By making comparisons an unknown levels of protein to known concentrations of Serum albumin, BSA is frequently used to identify the amount of many other proteins. It has been used because of its intention to boost signal in assays, its inhibitory effects in many biochemical processes, and it's relatively inexpensive due to the ease with which huge amounts of this can be reconstituted from bovine blood.

The novel virus SARS-CoV-2 (Severe acute respiratory syndrome) responsible for the current COVID-19 pandemic belongs to a category called severe acute respiratory syndrome-related coronavirus. SARS-CoV-2 can gain an entrance into the cell through the endosomes or by plasma membrane fusion mediated by Spike proteins using the angiotensin-converting enzyme 2 (ACE2) as the entry receptor [23]. When virions are taken up into endosomes, cathepsin $\mathrm{L}$ activates the spike protein. The spike protein can also be activated by the cellular serine protease TMPRSS2 in close proximity to the ACE2 receptor [23].

This activation initiates a fusion of the viral membrane with the plasma membrane [23]. This pathway is less likely to trigger a host cell antiviral immunity and is, therefore, more efficient for viral replication [24]. This is followed by uncoating of the virus and viral replication. The RNA-dependent RNA polymerase gene (RdRp) is responsible for the replication of structural protein RNA. The structural proteins are translated by ribosomes that are bound to the endoplasmic reticulum (ER) and presented on its surface as a preparation of the virion assembly. The nucleocapsids $(\mathrm{N})$ remain in the cytoplasm and are assembled from the genomic RNA. They fuse with the virion precursor which is then transported from the ER through the Golgi apparatus to the cell surface via small vesicles $[25,26]$. Virions are then released from the infected cell through exocytosis.

The outbreak of the COVID-19 pandemic has posed unrivaled challenges to individuals as well as health systems. Individuals with comorbidities have been reported to have increased tendencies for a severe infection as well as higher fatality from the SARS-CoV-2 virus. A Potential Target for Anti-COVID-19 therapies, one of the body's frontline immune defenses is a class of receptor proteins. Several researchers have been racing to understand the peculiar nature of the virus and the pathogenesis of the disease to uncover possible drug targets. Accordingly, numerous drug targets are identified by the present investigation. Several $\mathrm{N}$ - and O-donor-based bases are reported to possess remarkable antibacterial, antifungal, and anticancer activities. Thus, monitoring molecular docking 
levels in antiviral activity, antibacterial, anticancer, and antifungal activity is a promising target therapy for evaluating response to conventional COVID-19 treatments. The complexes N-Phenyl Anthranilic acid with Mg (II) has been found to show antibacterial and anticancer activity, respectively. Due to bacterial and viral resistance to the currently available antibiotics, there has been growing interest in developing new drugs with better activity. Since metal and ligand interact with various steps of the pathogen life cycle, they can be used to synthesize new drugs. Magnesium (II) metal complexes are assumed to act as antimicrobial agents due to inhibition of enzymes, interaction with intracellular biomolecules, and enhanced lipophilicity.

\section{Experiment Methods}

\subsection{Materials and Methods}

$N$-Phenylantranilic acid, Magnesium Sulphate, Celite, Silicagel received from Merck India and BSA from fluka were used as received. Acetone, Chloroform, Rectified spirit, Diethylether, and acetonitrile (AR, Merck) were used as received.

\subsection{UV-Visible Absorption Spectrum}

The electronic spectra were recorded in the 200-900 nm regions on Deep vision UV/VIS spectrophotometer using cuvette with a $1 \mathrm{~cm}$ path length. The concentration of ligand and metal complexes was kept at $1.00 \times 10^{-5} \mathrm{~mol} \mathrm{~L}^{-1}$, at $310 \mathrm{~K}$.

\subsection{BSA Binding Studies}

The absorption properties of the complexes in the existence of bovin serum albumin will be determined by treating the complexes in the midst of $4.5 \%$ bovin serum albumin in water (the content of albumin in cow) till equilibrium is accomplish and by measuring the absorption for the different time intervals of $30 \mathrm{mts}$ to 2 days. All absorption measurements were carried out in a UV-Visible spectrometer and the values are recorded at $310 \mathrm{~K}$.

2.4. CHN Microanalyses and Molecular docking study with SARS-Coronavirus-2 on the complexes has been performed using our reported procedure [27,28].

\subsection{Synthesis of Tris-N-Phenyl Antharanilic acid Mg(II) complex [Mg(T-N-PAA)]}

About $1.28 \mathrm{~g}(3 \mathrm{mMol})$ of $N$ - phenylantharanilic acid and $0.25 \mathrm{~g}(1 \mathrm{mMol})$ of $\mathrm{MgSO}_{4} .7 \mathrm{H}_{2} \mathrm{O}$ in $50 \mathrm{~mL}$ of chloroform, were heated at $80{ }^{\circ} \mathrm{C}$ under stirring for 24 hours. After the reaction was completed, the mixture was cooled to room temperature. The obtained clear solution was evaporated to dryness (Scheme-1).

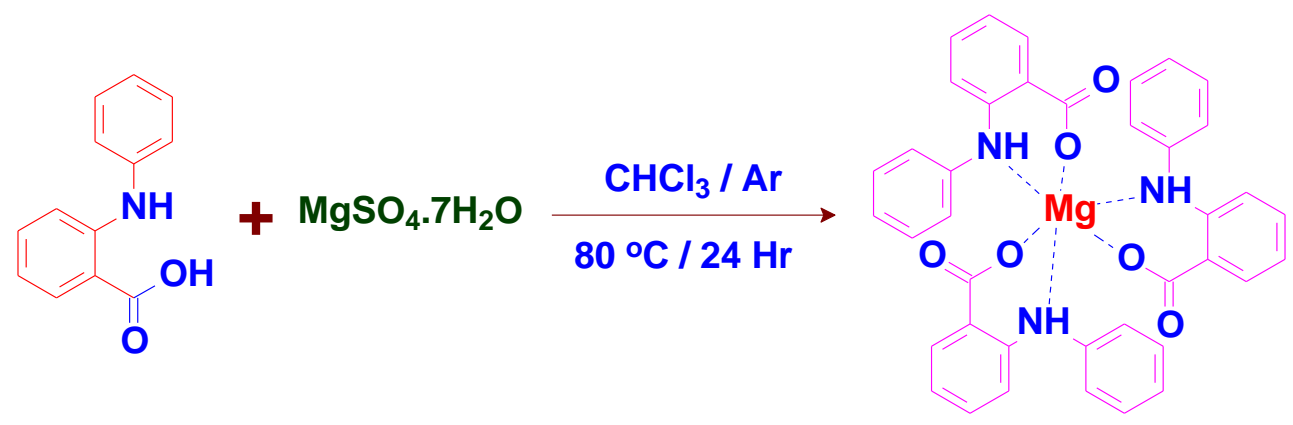

Scheme 1. Synthesis of $[\mathrm{Mg}(\mathrm{T}-\mathrm{N}-\mathrm{PAA})]$ complex 
The colorless [Mg(T-N-PAA)] complex obtained has been recrystallized from ethanol, yield $4.8 \mathrm{~g}(98 \%), \mathrm{mp}$ (dec.) $156{ }^{\circ} \mathrm{C}$. Anal. calcd. \% for $\mathrm{C}_{39} \mathrm{H}_{30} \mathrm{MgN}_{3} \mathrm{O}_{6}(\mathrm{Mr}=660.99): \mathrm{C}, 70.87 \% ; \mathrm{H}, 4.57 \% ; \mathrm{O}, 14.52 \%$; N, $6.36 \%$ $\mathrm{Mg}, 3.68 \%$. Found C, $70.77 \%$; H, $4.47 \%$; O, $14.42 \%$;, $6.26 \%$ Mg, $3.58 \%$.

\section{Result and Discussions}

\subsection{Theoretical Chemistry}

A molecule can possess different kinds of energy such as acquaintance and thermal energy. Molecular mechanics calculates the steric energy of a molecule--the energy due to the geometry or conformation of a molecule. Potential energy is an energy that is stored in substance.

This stored energy is based on the position, arrangement or state of the object or substance. It is an energy that has the 'potential' to do work. The potential and steric energies of the complex are given in Table-1.

Table 1. Calculated minimized energies for [Mg(T-N-PAA)] complex

\begin{tabular}{|l|l|}
\hline Calculated Values & {$[\mathrm{Mg}(\mathrm{T}-\mathrm{N}-\mathrm{PAA})]$} \\
\hline Stretch & 1.0112 \\
\hline Bend & 5.1459 \\
\hline Stretch-Bend & -0.1015 \\
\hline Torsion & -7.0004 \\
\hline Non-1.4 VDW & -0.6264 \\
\hline 1.4 VDW & 7.9884 \\
\hline Dipole Dipole & 4.8487 \\
\hline Total Energy & $11.2659 \mathrm{Kcal} / \mathrm{mol}$ \\
\hline Potential Energy & $11.364 \quad \pm 0.129$ \\
\hline Steric Energy & $86: 11.456 \mathrm{kcal} / \mathrm{mole}$ \\
\hline
\end{tabular}

\subsection{Electronic Absorption Spectroscopic study}

\subsubsection{Absorption spectrum of $[M g(T-N-P A A)]$ complex}

The UV-Vis absorbance spectrum of the Tris N-Phenyl Anthranilic acid Magnesium complex in ethanol is presented in Figure 1. The complex displays four distinctive intense peaks for the intra ligand $\left(\pi \rightarrow \pi^{*}\right)$ charge transfer transitions characteristics of anthracene derivatives at $382,364,352$ and $326 \mathrm{~nm}$. This absorption is authoritative to the spin-allowed metal-to-ligand charge transfer transitions (MLCT). 


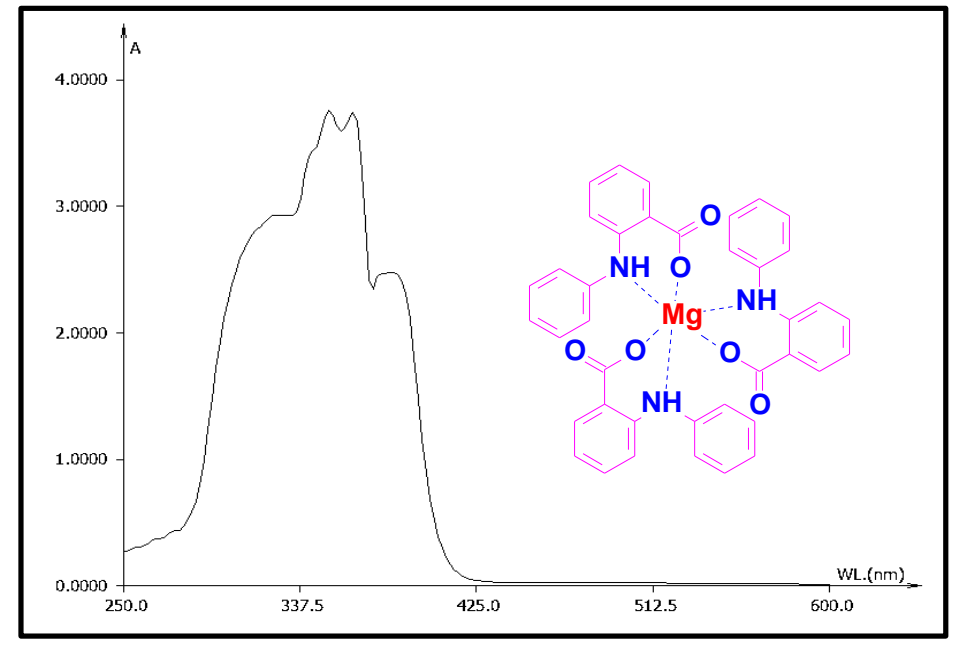

Fig.1. UV-VIS absorption spectrum of [Mg(T-N-PAA)] complex in water

\subsubsection{Absorption spectrum of $[M g(T-N-P A A)]$ complex with $B S A$}

The UV-Vis absorbance spectrum of the complex in water along with $4.5 \%$ of BSA is presented in figure 2. In the absorption spectrum, the complex put on show two distinct broad peaks for the intra ligand $\left(\pi \rightarrow \pi^{*}\right)$ charge transfer transitions characteristics of anthracene derivatives at 350 and $332 \mathrm{~nm}$. In the existence of BSA protein the absorption values for the complex is blue shifted owed to the polar interface of metal complex. The blue shift in the absorption value from 382 to $350 \mathrm{~nm}$ confirms the binding of the complex with BSA protein.

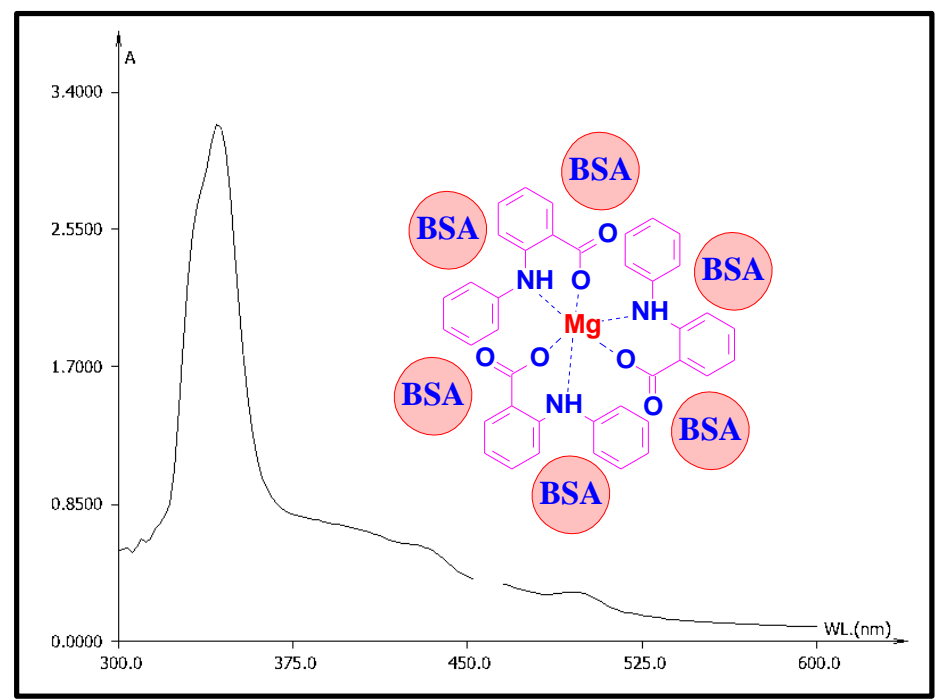

Fig.2. UV-VIS absorption spectrum of [Mg(T-N-PAA)] with BSA in water

\subsubsection{Molecular Docking study of [Mg(T-N-PAA)] complex with $6 L U 7$}

SARS-CoV-2 genome be full of single-stranded positive RNA put in a nutshell within a membrane wrap with an normal diameter of $75-150 \mathrm{~nm}$. The genome of SARS-CoV-2 has a length of about $30 \mathrm{~K}$ nucleotides. The elevated similarities of the amino acid sequences and envisage protein structures of the RBD domains of SARS-CoV-2 put it to somebody that it may resourcefully use human ACE2 as a receptor for cellular admission, which may perhaps potentially smooth the progress of human-to-human transmission. Subsequent to receptor-mediated endocytosis of 
the virus into the host cells, it releases viral genome, and using host ribosome decode into viral polyproteins. Viral proteinases 3CLpro and PLpro slice viral polyproteins into effectors proteins. $\mathrm{N}$ boundary protein attaches genomic RNA while 'S', 'M', and 'E' proteins are incorporated into the film of the endoplasmic reticulum (ER) forming ERGIC - endoplasmic reticulum-Golgi intermediary section. Assembled nucleocapsid with helical twisted RNA is encapsulated into the ER lumen, viral progeny is transported by the ERGIC toward the plasma membrane of the host cell, and at long last, descendant virus is released by exocytosis. By take advantage of computational tools, we have attempted to foretell and propose small molecule based antiviral and anti-cancer agents against various objective of SARS-CoV-2 viral and other deadliest cancer disease [29-32]. It is bring into being that the newly synthesized $\mathrm{Mg}$ (II) complex robustly hidden inside the spike proteins of SARS-COV-2 and attach well with the viral 3-chymotrypsin-like cysteine protease (3CLpro) enzyme which pedals reproduction of the SARSCoV virus. Our exceedingly polar [Mg(II)-T-N-PAA] complex combine through $\pi$-interaction with most important amino acids like, ARG-105, 298, ASP-153, 187, 197, ASN-238, GLN-110, 127, 273, GLY-179, ILE-152, LEU-272, PRO-52, THR-199, TYR-237 and VAL-186 with a coupling energy of -7.2 kcal mol ${ }^{-1}$. The well-built binding with the crowd molecule is attributed to the polar character of anthranilic acid and its compacted complex structure which has free ' $\mathrm{O}$ ' and ' $\mathrm{N}$ ' atom for abrupt anchoring. The plausible hydrogen bonding collaboration between the edifices with the dissimilar site on the receptor is prearranged in figure 3 .
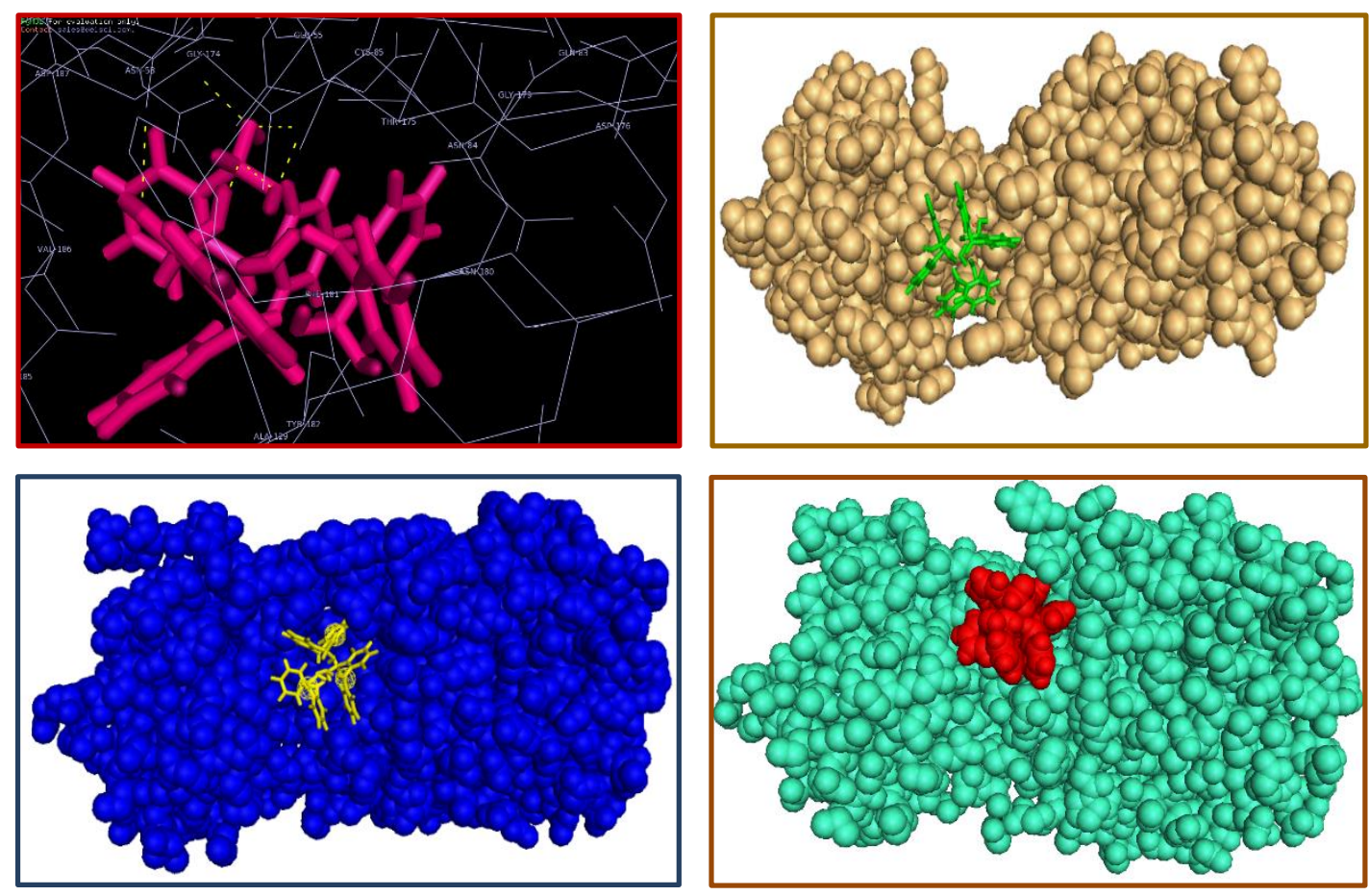

Fig.3. Molecular Docking Images of the complex with COVID-19 spike Protein (PDB No.: 6LU7)

\section{Conclusion}

Until now, there are no clinically supported therapeutics and immunizations for COVID-19 and its related disease. Accordingly, early and perfect identification followed by proper choice of antiviral treatment against SARS-CoV-2 infected people is the way to forestall extra transmission. The thermodynamically and kinetically stable small drugs are profoundly required in this pandemic. Our [Mg(T-N-PAA)] complex shows magnificent 
strength as far as potential and steric energy as affirmed by insilico Gaussian program. The communicated electronic retention conduct of the complex in regards to LCT and MLCT in pure solvent and in $4.5 \%$ BSA protein affirms the room temperature assimilation property of the complex. The adjustment of binding esteems because of hydrogen bonds and van der Waal's attraction demonstrates that the metal complex could be utilized for the optical-based examination of the deadliest microorganisms'. The best binding energy of $-7.2 \mathrm{kcal} / \mathrm{mol}$ when interacted with corona virus spike proteins (6LU7) make them a potential lead compound for the advancement of antiviral specialists against the SARS-COV-2. Our continuous antiviral investigation against COVID-19 will give a productive outcome against SARS-CoV-2 and other deadliest infections.

\section{Declarations}

\section{Source of Funding}

This research did not receive any specific grant from funding agencies in the public, commercial, or not-for-profit sectors.

\section{Competing Interests Statement}

The authors declare no competing financial, professional and personal interests.

\section{Ethical Approval}

Based on institutional guidelines.

\section{Consent to participate}

The consent to participate in this research was sought for and approved by the subjects to be used.

\section{Consent for publication}

Authors declare that they consented for the publication of this research work.

\section{Availability of data and material}

Authors are willing to share data and material according to the relevant needs.

\section{References}

[1] A. K. Singh, O. P. Pandey, and S. K. Sengupta, 'Molecular and Biomolecular Spectroscopy',, Spectrochimica Acta-Part A:, 2012, 85, 1-6.

[2] G. B. Bagihalli, P. G. Avaji, S. A. Patil, and P. S. Badami, European Journal of Medicinal Chemistry, 2008, 43, 2639-2649.

[3] R. Franski, B. Giercyzyk, G. Schroeder, S. Pieper, A. Springer, and M. Linscheid, Central European Journal of Chemistry, 2007, 5, 316-329.

[4] T. Mangamamba, M. C. Ganorkar, and G. Swarnabala, Int. J. of Inorganic Chemistry, 2014, 4, 21-30.

[5] Rai B.K, Kumari R, Orient J Chem2013, 29, 3. 
[6] M. H. Khalil, Eman H. Ismail, Gehad G. Mohamed, Ehab M. Zayed, Ahmed Badr. Open Journal of Inorganic Chemistry,2012, 2, 13-21.

[7] Surati, K.R. and Thake, B.T. Spectrochimica Acta A: Molecular and Biomolecular Spectroscopy, 2010, 75, $235-242$.

[8] Bharty, M.K., Srivastava, A.K., Dulwere, R., Butcher, R.J. and Singh, N.K. Polyhedron, 2011, 30, 990-996.

[9] Freiria, A., Bastida, R., Valencia, L., Macias, A., Lodeiro, C. Inorganica Chi. Acta, 2006, 359, 2383- 2394.

[10] Mobinikhaledi, N. Forughifar, and M. Kalhor, Turkish Journal of Chemistry, 2010, 34, 367-373.

[11] D. Prakash, C. Kumar, Journal of the Indian Chemical Society, 2009, 86, 1257-1261.

[12] L. Zapaha, J. Kalembkiewicz, Talanta, 2006, 69, 601.

[13] G. Ferguson, C. Glidewell, Acta Crystallogr, 2003, E59, m710

[14] B. Yan, H.J. Zhang, G.L. Zhou, J.Z. Ni, Chem Pap, 2003, 57, 82-83

[15] I. Leban, N. Grgurevic, J. Sieler, P. Segedin, Acta Crystallogr, 1997,C53, m854

[16] "Dietary Supplement Fact Sheet: Magnesium". Office of Dietary Supplements, US Nat. Institutes of Health. 11 February 2016.

[17] Blitz M, Blitz S, Hughes R, Diner B, Beasley R, Knopp J, Rowe BH "Aerosolized magnesium sulfate for acute asthma: a systematic review". Chest. 2005, 128, 337-44.

[18] "Committee Opinion No 652: Magnesium Sulfate Use in Obstetrics". Obs. \& Gynecology. 2016, 27, e52-53.

[19] Crowther, C, A.; Brown, J; McKinlay, Christopher J. D.; Middleton, Philippa "Magnesium sulphate for preventing preterm birth in threatened preterm labour". The Cochrane Database of Systematic Reviews, 2014, 15. [20] James MF "Magnesium in obstetrics". Best Pract Res Clin Obstet Gynaecol. 2010, 24, 327-337.

[21] Euser, A. G.; Cipolla, M. J. "Magnesium Sulfate for the Treatment of Eclampsia: A Brief Review". Stroke. 2009, 40, 1169-1175.

[22] Giannini, A. J. (1997). Drugs of Abuse (Second ed.). Los Angeles: Physicians Management Information Co. [23] Joydeb Majumder, J., Minko, T., 'Recent Developments on Therapeutic and Diagnostic Approaches for COVID-19' The AAPS Journal, 2021, 23, 1-22.

[24] M. Hoffmann, et al., SARS-CoV-2 Cell Entry Depends on ACE2 and TMPRSS2 and Is Blocked by a Clinically Proven Protease Inhibitor, Cell, 2020, 181, 271-280.

[25] K. Shirato, et al., A pathological report of three COVID-19 cases by minimally invasive autopsies, J. Virol. 2020, 2, 1-9.

[26] J.L. Mckimm-Breschkin, "Influenza neuraminidase inhibitors: Antiviral action and mechanisms of resistance,” Influenza Other Respi. Viruses, 2013, 7, pp. 25-36.

[27] Pushparaj L T., Alexander, V. 'Trinuclear Gd(III) Metal Complex with Amide Core Display Remarkable Enhancement in Relaxivity’. App. Mag. Res., 2017, 48, 813-825. 
[28] Trott, O., Olson, A. J. AutoDock Vina: improving the speed and accuracy of docking with a new scoring function, efficient optimization and multithreading, J. Comp. Chem., 2010, 31, 455-461.

[29] Pushparaj L.T., Francy I.R.E., M.Uma, D.M. 'HSA and CA-125 Binding Study of [Pr-(DO3-Ch-Ph-Am-Gd (III))2Pt(IV)] Complex as M-MRI Contrast Agent for Ovarian Cancer Treatment'. JIDPTS, 2021, 4, 1-8.

[30] Pushparaj L T., Francy I R E., Sathya, S. ‘Therapeutic Properties of Gd(III)-Ir(III) Complex for Non-invasive Detection of Ovarian Cancer Through M-MR Imaging', IIJSR, 2021, 5, 23-33.

[31] Pushparaj L T., Sathya, S. 'Novel Designing of Ir(III)(Tris-Coumarin) Cored Gd(III) Complex as Targeted MRI CAs for Ovarian Cancer Treatment'. IIJSR, 2021, 5, 7-17.

[32] Pushparaj L T., Uma, D M. 'Developing Novel Coumarone-Phenyl Amide Functionalized [Gd(III)-Pt(IV)] Complex as High T1, T2 Relaxive M-MRI Contrast Agent for Cancer Diagnosis'. IIJSR, 2021, 5, 51-63. 